\title{
Recurrent Skin Carcinoma
}

National Cancer Institute

\section{Source}

National Cancer Institute. Recurrent Skin Carcinoma. NCI Thesaurus. Code C7903.

A carcinoma of the skin that has recurred after a period of remission. 